\title{
A Path Analysis Model for Explaining the Factors Influencing Wearing a Mask among Commuting Workers Using Commuter Line Bogor-Jakarta
}

\author{
David Kusmawan ${ }^{*}$, Shofi Andari ${ }^{2,3}$, Ira Gustina ${ }^{4}$, Indri H Susilowati ${ }^{5}$, Mufti Wirawan ${ }^{5}$
}

\author{
${ }^{1}$ Program Study of Public Health, Faculty of Medicine and Health Science, Universitas Jambi, Jambi, Indonesia \\ 2Bioinformatics and Computational Biology Graduate Program, Iowa State University, USA \\ ${ }^{3}$ Department of Statistics, Faculty of Science and Data Analytics, Institut Teknologi Sepuluh Nopember (ITS), Surabaya, Indonesia \\ ${ }^{4}$ Statistics Clinic Research Center, Indonesia \\ ${ }^{5}$ Department of Occupational Health and Safety, Faculty of Public Health, Universitas Indonesia, Depok, Indonesia
}

\begin{abstract}
Jakarta is one of the most air-polluted cities in the world, which can increase the health risk of commuting workers exposed to pollutants. This study aimed to determine the factors that directly and indirectly affect healthy behavior (wearing a mask) for commuters using the Bogor-Jakarta Commuter Line. Furthermore, a total of 155 respondents participated and the data collected were analyzed using descriptive and path analysis. The commuters aware of the hazard potential related to air pollution during commuting were 137 people (88.4\%). While 104 people $(67.1 \%)$ were aware of the good perception of pollution and 125 uses masks during commuting (80.6\%). The healthy behavior in commuting workers using Commuter Line was affected by some factors, both directly and indirectly. The knowledge and commuting experience toward healthy behavior were two variables that significantly influenced on healthy behavior. The knowledge was also the only mediated variable with a significant indirect effect of education on healthy behavior.
\end{abstract}

Keywords: commuting workers, healthy behavior, Commuter Line, mask, path analysis

\section{Introduction}

Numerous studies have shown that workplace accidents have occurred due to commuting and health risks from pollution. ${ }^{1}$ Air pollution is a major environmental risk to health. The government can reduce the burden of disease from stroke, heart disease, lung cancer, and both chronic and acute respiratory diseases, including asthma, acute lower respiratory, chronic obstructive pulmonary disease, stroke, ischemic heart disease, and lung cancer by reducing air pollution. ${ }^{1}$ Meanwhile, a student's exposure to air pollution can increase the health risk associated with neurodegenerative aging processes. ${ }^{2}$

Jakarta is one of the most air-polluted cities in the world, which can increase the health risk of its commuting workers exposed to pollutants. In Jakarta, Bogor, Depok, Tangerang, and Bekasi (Jabodetabek) City, the number of commuters continued to increase from 6 to 7 million in 2014, and they are at risk of being exposed to particulate matter (PM). The level of exposure was influenced by the mode of transportation used as reported in the study conducted by Gilliland, et al. ${ }^{3}$ Another dangerous pollutant exposure is ultrafine particles (UFPs), 4,5 with an increased level of urinary 1-Hydroxypyrene (1-

Correspondence *: David Kusumawan, Program Study of Public Health, Faculty of Medicine and Health Science, Universitas Jambi, Letjen Suprapto Street, Telanipura, Jambi City, Indonesia, E-mail: kusmawandavid@gmail.com, Phone: +628984844020
OHP), which is a biomarker of polycyclic aromatic hydrocarbons (PAHs) exposure in urine, ${ }^{6}$ pleural anthracosis, ${ }^{7}$ a respiratory disorder due to air pollution, ${ }^{4}$ and ischemic heart disease due to transportation noise exposure. 8

According to the theory of the Health Belief Model developed by Rosenstock with assumptions of an individual suffering from a disease, they become more aware of prevention and protection or healthy behavior, such as wearing personal protective equipment (PPE) and mask in the workplace and when commuting to work. Furthermore, healthy behavior at work is needed to reduce the risk of accidents and health. The lack of hazardous knowledge in the workplace can increase the workers' accidents and health risks. ${ }^{9}$ The previous study related to commuters using Commuter Line BogorJakarta reported the perception of inconvenience when commuting to work. About $67.1 \%$ of respondents stated that they felt uncomfortable with the air pollution while commuting to work. ${ }^{10}$

Previous study has been conducted on healthy behavior in working with various workplace settings. ${ }^{9}$ However, the information related to the factors influenc- 
ing healthy behavior, especially for commuter workers wearing a mask when commuting to work, has not been clear until now. This study aimed to determine the influencing factors of health behavior in commuting activities, especially wearing a mask for commuter workers using the Commuter Line to work from Bogor to Jakarta, directly and indirectly. Furthermore, this study used descriptive and path analysis.

\section{Method}

The first model to explain the factors that influenced the wearing of a mask is based on several hypothesis, $\left(\mathrm{H}_{1}\right)$ knowledge of the risk of contamination which directly affects the wearing of a mask, $\left(\mathrm{H}_{2}\right)$ experience of using Commuter Line, which has a direct impact on wearing mask, $\left(\mathrm{H}_{3}\right)$ the level of income has a direct impact on wearing mask, $\left(\mathrm{H}_{4}\right)$ knowledge has an indirect effect on wearing mask mediated by inconveniences perception with pollution, $\left(\mathrm{H}_{5}\right)$ the experience of using Commuter Line has an indirect effect on wearing mask mediated by the pollution inconveniences perception, $\left(\mathrm{H}_{6}\right)$ the level of education has an indirect effect on wearing of mask, mediated by the pollution inconveniences perception, $\left(\mathrm{H}_{7}\right)$ the experience of using Commuter Line has an indirect effect on wearing mask, mediated by the knowledge and pollution inconveniences perception, $\left(\mathrm{H}_{8}\right)$ the education has an indirect effect on wearing of mask, mediated by the knowledge and pollution inconveniences perception, $\left(\mathrm{H}_{9}\right)$ the education has an indirect effect on wearing mask mediated by the knowledge.

This preliminary study was part of the study on the quality of life (QOL) of commuting workers using the Commuter Line and Busway (Transjakarta) from Bogor to Jakarta in 2018 with the WHO QOL BREF questionnaire and some additional questions about knowledge in pollutant risk. Furthermore, an applied cross-sectional design was applied with a total of 155 respondents of commuting workers using Commuter Line Bogor-Jakarta in 2018. A pilot survey involving 30 pre-test subjects was carried out to check the validity and reliability of the questionnaire and later on, was distributed via Google Form. A brief assessment was carried out and the incompletely answered questionnaire was not excluded from the study. Finally, 155 completed questionnaires were qualified to be used in the analysis. The questionnaire consists of questions in demographic characteristics (name, sex, education, job characteristics, salary, marital status), the experience of using Commuter Line, knowledge of pollutants risk exposure. The knowledge of pollutants risks exposure measured by mentioning what kinds of contaminants respondents know (vehicle emission, PAHs, PM), using a mask when going to work or not). In this study, six variables were used following the hypothesis.
The dependent variable was wearing a mask and the independent variables were knowledge, commuting experience, education, income, and discomfort perception with pollution. The knowledge arises from knowing a potential hazard related to air pollution when using Commuter Line. Commuting experience is defined as traveling for less and more than two years. Furthermore, education was the highest formal education attained by the commuter, less than or equal to senior high school (SHS) and higher. ${ }^{10}$ Income is a total income per month of the commuter, using provincial minimum wage (less than equal 3 million/low and above 3 million/high). Discomfort perception with pollution is defined commuters feel discomfort with pollution during commuting (measured of 1-10 scale, good is more than median score and vice versa).

Descriptive analysis was used to explain the demographic characteristics of the respondents (name, sex, education, job characteristics, salary, marital status). Then a path analysis was carried out by using proprietary statistical software package, which is a tool for assessing the direct and indirect effects of some variables on a specific target variables that was healthy behavior. The direct effect meant that it would be affected without an intermediate dependent variable $\left(\mathrm{H}_{1}, \mathrm{H}_{2}, \mathrm{H}_{3}\right)$ while indirect effect had intermediary variable to dependent variable $\left(\mathrm{H}_{4}, \mathrm{H}_{5}, \mathrm{H}_{6}, \mathrm{H}_{7}, \mathrm{H}_{8}, \mathrm{H}_{9}\right)$. The strength of a path was represented by a coefficient conceptually equal to the standardized partial regression coefficients. A coefficient had a range from -1 to +1 . The higher the coefficient, the greater the effect of one variable on another. The t-value, which is the ratio of the unstandardized estimate to standard error, was used to assess the significance of a path in a path analysis model: if $t$-value $>1.96$, the path was significant at 0.05 .

In addition to each path, the suitability of a path analysis model can also be determined using indices available for such evaluations. These indices can be categorized into two main groups, absolute fit indices and comparative fit indices. Furthermore, absolute fit indicated outline how well the hypothesized model fits the data. ${ }^{11}$ The model $\chi^{2}$ value, Root Mean Square Error of Approximation (RMSEA), suitability of Goodness Fit Index (GFI), and Root Mean Square Residual (RMR) were some indices categorized in the group. ${ }^{11}$

The model $\chi^{2}$ value was very sensitive to the sample size and typically its value increases as the sample size increases. To solve this problem, it is proposed to use the ratio of the value $\chi^{2}$ to the degree of freedom (df) in such a way that a ratio of less than two indicates of a satisfactory adaptation of the model. ${ }^{11}$ An RMSEA was another absolute fit index, popular because of its informative and easy to interpret nature. This index was calculated using the model $\chi^{2}$ value, df, and sample size $(\mathrm{N})$ 


$$
\text { RMSEA }=\frac{\sqrt{x^{2}-d f}}{d f(N-1)},(1)
$$

Formula 1. Root Mean Square Error of Approximation

(Formula 1). ${ }^{12}$ An RMSEA value lower than 0.07 indicates a good fit, values lower than 0.1 were indicative of mediocre fit, and values higher than 0.1 represent unacceptable model fit, ${ }^{11}$ as potrayed in the Formula 1. Where the RMSEA, root mean square error of approximation, $\chi^{2}$ is the chi-square value of the model, $\mathrm{N}$ is a sample size.

In contrast, comparative fit indices, e.g., Normal Fit Index (NFI) and Comparative Fit Index (CFI), explain how close the hypothesized model is to a baseline ideal model. Moreover, comparative fit indices with values higher than 0.95 indicate that a model is of good fit. ${ }^{11}$

\section{Results}

The data obtained from the questionnaire regarding the characteristics of participants are summarized in Table 1. Based on the hypothesis, a model path analysis was constructed. Table 2 presents the fit indices of the path model in the present study. From the table, the ratio of the $\chi^{2}$ value to the degree of freedom (df) is lower than two $(2.24 / 3=0.746)$, RMSEA $<0.07(0.00)$, Incremental Fit Index (IFI) $>0.95$ (1.015), GFI $>0.95$ (0.995), and CFI $>0.95$ (1.000). It can be concluded that the overall fit indices are acceptable on the model.

From the model (Figure 1), the factors affected wearing a mask is presented in different ways: (1) direct path from knowledge; (2) direct path from commuting experience (using Commuter Line); (3) direct path from in- come; (4) indirect path from knowledge, which was mediated by discomfort perception with pollution; (5) indirect path from commuting experience, which was mediated by discomfort perception with pollution; (6) indirect path from education, which was mediated by discomfort perception with pollution; (7) indirect path from commuting experience, which was mediated by knowledge and discomfort perception with pollution; (8) indirect

Table 1. Characteristic of Commuting Worker Using Commuter Line BogorJakarta 2018

\begin{tabular}{llrr}
\hline Variable & Category & N & $\%$ \\
\hline Knowledge & Good & 137 & 88.4 \\
Commuting experience (using Commuter Line) & Bad & 18 & 11.6 \\
& $<2$ years & 23 & 14.8 \\
Education & $\geq 2$ years & 132 & 85.2 \\
& SSHS & 12 & 7.7 \\
Income & >SHS & 143 & 92.3 \\
& Low & 56 & 36.1 \\
Discomfort perception with pollution & High & 99 & 63.9 \\
& Good & 51 & 32.9 \\
Healthy behavior (wearing mask) & Bad & 104 & 67.1 \\
& Good & 125 & 80.6 \\
& Bad & 30 & 19.4 \\
\hline
\end{tabular}

Note: SHS = Senior High School

Table 2. Various Fit Indices of the Model

\begin{tabular}{lrcl}
\hline Model Fit Index & Estimation Result & Acceptable Level & Conclusion \\
\hline & $\mathrm{df}=3$ & & \\
$\chi^{2 / \mathrm{df}}$ & $\chi^{2}=2.24$ & $<2.00$ & Fit \\
RMSEA & 0.00 & $<0.07$ & Fit \\
IFI & 1.015 & $>0.95$ & Fit \\
GFI & 0.995 & $>0.95$ & Fit \\
CFI & 1.000 & $>0.95$ & Fit \\
\hline
\end{tabular}

Notes: $\mathrm{df}=$ degree of freedom, RMSEA = Root Mean Square Error Approximation, IFI = Incremental Fit Index, CFI = Comparative Fit Index, GFI $=$ Goodness of Fit Index

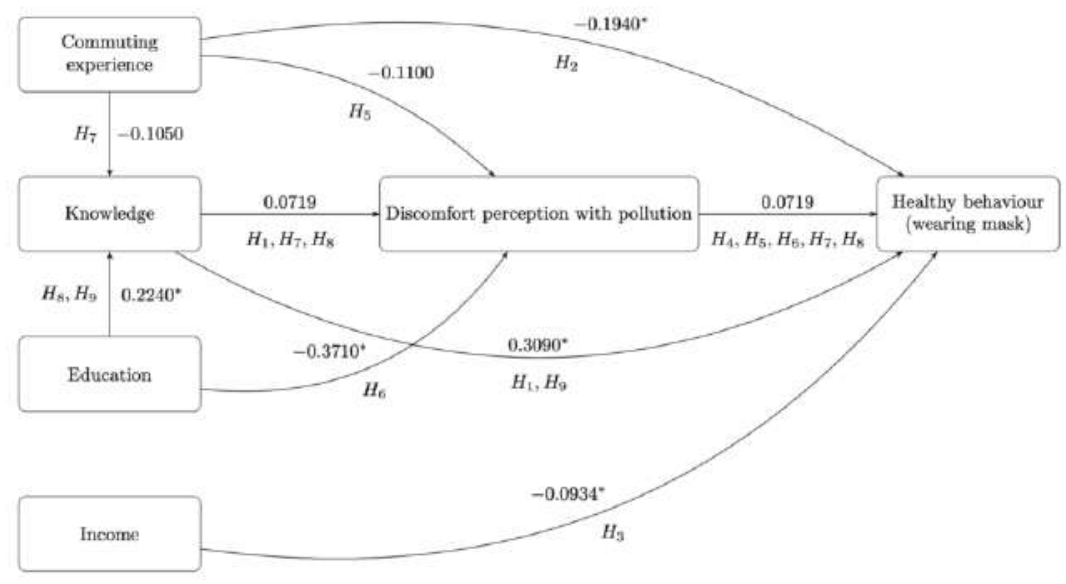

Noted: *Significant effect

Figure 1. The Path Model for Explaining Factors to Wear a Mask among Commuting Workers using Commuter Line Bogor-Jakarta 
path from education, which was mediated by knowledge and discomfort perception with pollution; and (9) indirect path from education, mediated by knowledge.

The variables that affected wearing a mask are presented in four different ways; (1) direct effect $\left(\mathrm{H}_{1}, \mathrm{H}_{2}\right.$, $\left.\mathrm{H}_{3}\right)$; (2) the effect mediated by knowledge $\left(\mathrm{H}_{9}\right)$; (4) the effect mediated by discomfort perception $\left(\mathrm{H}_{4}, \mathrm{H}_{5}, \mathrm{H}_{6}\right)$; and (3) the effect mediated by knowledge and discomfort perception $\left(\mathrm{H}_{7}, \mathrm{H}_{8}\right)$. As shown in the path model (Figure1), it is evident from the data, which concludes as follows: (1) knowledge and commuting experience towards wearing a mask are two variables with a significant direct effect ( $\mathrm{t}$ value on $\mathrm{H}_{1}$ and $\mathrm{H}_{2}$ were more than 1.96), while income was not a significant direct effect ( $p$-value on $\mathrm{H}_{3}$ was less than 1.96); (2) knowledge was also the only mediated variable with a significant indirect effect of education on wearing a mask ( $\mathrm{t}$-value on $\mathrm{H}_{9}$ wasmore than 1.96). Therefore education has an indirect effect on wearing a mask; (3) discomfort perception is not an intervening variable on the effect of knowledge, commuting experience, and education on wearing a mask where the path on $\mathrm{H}_{4}, \mathrm{H}_{5}$, and $\mathrm{H}_{6}$ was not significant (t-value < 1.96). Interestingly, it was demonstrated that the influence of knowledge, commuting experience, and education towards wearing a mask was not mediated by inconveniences perception with pollution. Knowledge and discomfort perception were not intervening variables on the effect of commuting experience and education on wearing a mask where the path on $\mathrm{H}_{7}$ and $\mathrm{H}_{8}$ were less than 1.96. From this path, it was concluded that the commuting experience and education has no indirect effect on wearing a mask mediated by knowledge and discomfort perception.

Table 3 presents all statistics on each path. This, along with the model shown in Figure 1, provides the lead of the variable that has the most significant direct effect on wearing a mask, which is the knowledge of the importance of wearing a mask related to the hazard of the pollutant. Furthermore, it is followed by commuting experience using Commuter Line Bogor-Jakarta. Moreover, education has an indirect effect on wearing a mask mediated by knowledge. From the significant path coefficient, it can be concluded that (1) The direct effect of knowledge on wearing a mask has a positive path coefficient of 0.309 (odds ratio $(\mathrm{OR})=\mathrm{e}^{0.309}=1.36$ ); (2) the indirect effect of commuting experience on wearing a mask has a negative path coefficient of $-0.194\left(\mathrm{OR}=\mathrm{e}^{-0.194}=0.82\right)$; and (3) the indirect effect of education on wearing a mask mediated by knowledge (education*knowledge*wearing a mask) has the coefficient effect of $0.224 * 0.309=0.069\left(\mathrm{OR}=\mathrm{e}^{0.069}=1.07\right)$.

Using a path analysis model, not only to quantify the direct effect but also able to quantify the indirect effects that variables have on each other. Table 4 presents these quantities for each variable in the path coefficient column. As shown on the table, knowledge was the variable with the highest direct effect on wearing a mask (0.309).

\section{Discussion}

Currently, wearing a mask is very important during the Coronavirus disease 2019 (COVID-19) pandemic. Using a mask both in public transport and workplace is the key recommended practices for health protocol. This study produced three important findings related to wear-

Table 3. The Significance Level of Each Path in the Models

\begin{tabular}{|c|c|c|c|c|}
\hline \multicolumn{2}{|l|}{ Path } & \multirow{2}{*}{ Standardized Path Coefficient } & \multirow{2}{*}{ SE } & \multirow{2}{*}{ t } \\
\hline From & To & & & \\
\hline Commuting experience & Knowledge & 0.105 & 0.071 & 1.465 \\
\hline Education & Knowledge & $0.224 *$ & 0.095 & 2.349 \\
\hline Knowledge & Discomfort perception with pollution & 0.071 & 0.119 & 0.603 \\
\hline Commuting experience & Discomfort perception with pollution & -0.110 & 0.106 & -0.104 \\
\hline Education & Discomfort perception with pollution & $-0.371^{*}$ & 0.142 & -2.605 \\
\hline Knowledge & Wearing a mask & $0.309 *$ & 0.095 & 3.245 \\
\hline Commuting experience & Wearing a mask & $-0.194 *$ & 0.088 & -2.184 \\
\hline Income & Wearing a mask & -0.093 & 0.065 & -1.436 \\
\hline Discomfort perception with pollution & Wearing a mask & -0.103 & 0.065 & -1.600 \\
\hline
\end{tabular}

Note: *(Significant) if $\mathrm{t}>1.96 ; \mathrm{SE}=$ Standard Error

Table 4. Direct, Indirect, and Total Effects of the Variables on Wearing Mask

\begin{tabular}{lrrr}
\hline Variable & Direct Effect & Indirect Effect & Total Effect \\
\hline Knowledge & -0.309 & 0.0005 & 0.3038 \\
Commuting experience with Commuter Line & -0.0194 & -0.0084518 & -0.0278 \\
Education & - & -0.0255 & -0.0255 \\
Discomfort perception with pollution & 0.0719 & - & 0.0719 \\
Income & -.0934 & - & -0.0934 \\
\hline
\end{tabular}


ing a mask of commuter workers using Commuter Line transportation.

The factors that directly and indirectly influenced wearing a mask were factors of knowledge, education and risk perception. This finding was in line with the factors affecting workers/community that influence wearing a mask during the COVID-19 pandemic. ${ }^{20}$ The direct effect of knowledge on wearing a mask had a positive path coefficient of 0.309 (odds ratio $(\mathrm{OR})=\mathrm{e}^{0.309}=1.36$ ). As a result, the commuter that knew about the potential hazard of air pollution had OR to wear masks by 1.36 units higher than commuters that do not know.

The direct effect of commuting experience on wearing a mask has a negative path coefficient of $-0.194\left(\mathrm{OR}=\mathrm{e}^{-}\right.$ $0.194=0.82)$. Therefore, the commuter with experience using the Commuter Line Bogor-Jakarta for more than equal two years had OR to wear a mask by 0.82 units lower than the commuter with experience less than two years using Commuter Line Bogor-Jakarta. In other words, commuters with experience in using the Commuter Line Bogor-Jakarta for less than two years have OR to wear mask 1.22 units higher than commuters with an experience of more than equal two years.

The indirect effect of education on wearing a mask mediated by knowledge (education to knowledge to wearing a mask) has a coefficient effect of $0.224 * 0.309$ $=0.069\left(\mathrm{OR}=\mathrm{e}^{0.069}=1.07\right)$. Therefore, the commuter with higher education than SHS had OR to wear a mask by 1.07 units, higher than the commuters with lower educational level than SHS.

Healthy behavior is required during labor. Most study related to healthy and safe behavior are being carried out in the workplace. ${ }^{9,13,14}$ However, a study has also shown that safe behavior is important in commuting activities, especially in the transportation industry. ${ }^{14}$ In this study, the assessment of healthy behavior related to wearing a mask was carried out for commuters using Commuter Line Bogor-Jakarta. Furthermore, wearing a mask is one of the indicators studied concerning healthy behavior because it reduces the risk of exposure to various pollutants. ${ }^{15,16}$ This study reported that knowledge of the risk of contaminants was the greatest significant effect directly on safety or healthy behavior (wearing a mask). This result is in line with the findings of the previous study, according to Ghasemi, et al. ${ }^{17}$

Previous study showed that the perception of risk was directly significant to healthy or safe behavior. ${ }^{18}$ However, this study also demonstrated that the discomfort perception about pollution (bad and good) did not significantly affect the commuter wearing a mask both as a direct and indirect effect (intermediary factor) through knowledge, commuter experience, and education. Furthermore, the perception of pollution was only measured by bad and good. The perception of risk of hazard (pollution) could affect commuters in healthy behavior; therefore, the bad perception of inconvenience feeling about pollution is not dangerous for them, especially from an occupational health and safety perspective. There was a positive effect between perceived severity and preventive behavior, and people with a high perceived severity increased preventive behavior compared to people with low perceived severity. In summary, the model presented provides important findings on how the effects of wearing a mask on healthy behavior are not mediated by other variables such as perceived complaints about pollution.

Path analysis is a powerful method for assessing direct and indirect impacts, but it has limitations. Some of these limitations are discussed by Jeon. For example, path analysis can only be used for explanation and not for prediction. ${ }^{18,19}$ This study also needs a qualitative method to investigate further and validate healthy and safe behavior. The bias may arise from the distributed questionnaires. However, this problem has been minimized by conducting the validity and reliability test of the questionnaire.

Despite the limitations of this study, the findings contributes to the literature with important information on healthy behavior related to wearing a mask for commuting workers

\section{Conclusion}

The healthy behavior (wearing a mask) for commuting workers using Commuter Line Bogor-Jakarta is influenced by some factors, both directly and indirectly. The knowledge and commuting experience towards healthy behavior were two variables with a significant direct influence on healthy behavior. Knowledge was also the only mediated variable with a significant indirect effect of education on healthy behavior.

\begin{abstract}
Abbreviations
PM: Particulate Matter; UFPs: Ultrafine Particles; 1-OHP: 1Hydroxypyrene; PAHs: PolycyclicAromatic Hydrocarbons; PPE: Personal Protective Equipment; QOL: Quality of Life; SHS: Senior High School; df: Degree of Freedom; RMSEA: Root Mean Square Error of Approximation; GFI: Goodness Fits Index; RMR: Root Mean Square Residual; NFI: Normal Fit Index; CFI: Comparative Fit Index; IFI: Incremental Fit Index; Covid-19: Coronavirus disease 2019; OR: Odd Ratio.
\end{abstract}

\section{Ethics Approval and Consent to Participate}

The study questionnaire was approved in regards to ethical studies by the Directorate of Research and Community Service, Faculty of Public Health, Universitas Indonesia with Approval Number 296/UN2.F10PPM.00.02/2018.industr

Competing Interest 
The author declares that there are no significant competing financial, professional, or personal interests that might have affected the performance or presentation of the work described in this manuscript.

\section{Availability of Data and Materials}

The authors confirm that the data supporting the finding of this study are available within the article and its supplementary materials.

\section{Authors' Contribution}

DK was the principal investigator of the study. DK managed data collection, controlled the framework and reporting. IG was in charge of statistical analysis and their interpretation. SA was collaborating in writing the manuscript. HIS and MW support grant for collecting data.

\section{Acknowledgment}

The study is funded by The Directorate of Research and Community Engagement of Universitas Indonesia 2018.

\section{References}

1. World Health Organization. Ambient air pollution: a global assessment of exposure and burden of disease; 2016.

2. Woodward N, Haghani A, Johnson R, Hsu T, Saffari A, Sioutas C, et al. Prenatal and early life exposure to air pollution induced hippocampal vascular leakage and impaired neurogenesis in association with behavioral deficits. Translational Psychiatry. 2018; 8: 261.

3. Gilliland J, Maltby M, Xu X, Luginaah I, Loebach J, Shah T. Is active travel a breath of fresh air? Examining children's exposure to air pollution during the school commute. Spatial and Spatio-temporal Epidemiology. 2019; 29: 51-7.

4. Zuurbier M, Hoek G, Oldenwening M, Meliefste K, van den Hazel P, Brunekreef B. Respiratory effects of commuters' exposure to air pollution in traffic. Epidemiology. 2011: 219-27.

5. Knibbs LD, Cole-Hunter T, Morawska L. A review of commuter exposure to ultrafine particles and its health effects. Atmospheric Environment. 2011; 45: 2611-22.

6. Miao Q, Bouchard M, Chen D, Rosenberg MW, Aronson KJ. Commuting behaviors and exposure to air pollution in Montreal, Canada. Science of the Total Environment. 2015; 508: 193.

7. Takano APC, Justo LT, dos Santos NV, Marquezini MV, de André PA, da Rocha FMM, et al. Pleural anthracosis as an indicator of lifetime exposure to urban air pollution: an autopsy-based study in Sao Paulo. Environmental Research. 2019; 173: 23-32.

8. Vienneau D, Schindler C, Perez L, Probst-Hensch N, Röösli M. The relationship between transportation noise exposure and ischemic heart disease: a meta-analysis. Environmental Research. 2015; 138: 372-80.
9. Pandit B, Albert A, Patil Y, Al-Bayati AJ. Impact of safety climate on hazard recognition and safety risk perception. Safety Science. 2019; 113: 44-53.

10. Kusmawan D, Susilowati IH, Wirawan M. Study of quality of life at worker user train commuter line and transjakarta busway Bogor-Jakarta 2018. Indian Journal of Public Health Research \& Development. 2018; 9.

11. Hooper D, Coughlan J, Mullen M. Structural equation modelling: guidelines for determining model fit. Articles. 2008: 2.

12. Kline RB. Principles and practice of structural equation modeling. Guilford Publications; 2015.

13. Fogarty GJ, Shaw A. Safety climate and the theory of planned behavior: towards the prediction of unsafe behavior. Accident Analysis \& Prevention. 2010; 42: 1455-9.

14. Hazavehei S, Shadzi S, Asgari T, Pourabdian S, Hasanzadeh A. The effect of safety education based on health belief model (HBM) on the workers practice of Borujen industrial town in using the personal protection respiratory equipments. Iran Occupational Health. 2008; 5: 21 30.

15. Patel D, Shibata T, Wilson J, Maidin A. Challenges in evaluating PM concentration levels, commuting exposure, and mask efficacy in reducing PM exposure in growing, urban communities in a developing country. Science of The Total Environment. 2016; 543: 416-24.

16. Pacitto A, Amato F, Salmatonidis A, Moreno T, Alastuey A, Reche C, et al. Effectiveness of commercial face masks to reduce personal PM exposure. Science of The Total Environment. 2019; 650: 1582-90.

17. Ghasemi F, Kalatpour O, Moghimbeigi A, Mohhamadfam I. A path analysis model for explaining unsafe behavior in workplaces: the effect of perceived work pressure. International journal of occupational safety and ergonomics. 2018; 24: 303-10.

18. Dewi RD, Rahardjo SS, Murti B. Path analysis on the factors affecting the use of personal protection equipment among airport construction workers in Yogyakarta. Journal of Health Promotion and Behavior. 2019; 4: 12-21.

19. Jeon J. The strengths and limitations of the statistical modeling of complex social phenomenon: focusing on SEM, path analysis, or multiple regression models. nternational Journal of Social, Behavioral, Educational, Economic, Business and Industrial Engineering. 2015; 9: 1594-602.

20. Irfan M, Akhtar N, Ahmad M, Shahzad F, Elavarasan RM, Wu H, Yang C. Assessing public willingness to wear face masks during the COVID19 pandemic: fresh insights from the theory of planned behavior. International Journal of Environmental Research and Public Health. 2021;18 (9): 4577. 